\title{
Fracture mechanics as an improvement of fatigue life assessment in orthotropic bridge decks
}

\author{
W. Nagy, H. De Backer \& Ph. Van Bogaert \\ Ghent University, Ghent, Belgium
}

\begin{abstract}
Orthotropic bridge decks are widely used in long span steel bridges since they are extremely light weighted when compared with the load carrying capacity. In the past, fatigue life problems have sometimes been overlooked during design. Nowadays, approaches for fatigue design have reached their limits resulting in conservative design leading to overestimating the necessary dimensions. An improved fatigue life assessment method is thus necessary. One possibility is to start using fracture mechanics. These techniques have many advantages since they form a more in-depth analysis. This implies that an entire crack propagation can be evaluated. If the case study of the Temse bridge in Belgium is evaluated, a crack length of $461,703 \mathrm{~mm}$ is found while a crack length of $600 \mathrm{~mm}$ was detected in reality. Although the results show the effort of fracture mechanics, improvements are still necessary such as implementing residual stresses into the model.
\end{abstract}

\section{INTRODUCTION}

Although fatigue in steel constructions is the most important form of fracture, it is the least understood behaviour because of its complexity. In the past, fatigue life problems have sometimes been overlooked during design. Fatigue as a failure mode first came to light in the mid-nineteenth century with Wöhler's research work in Germany on the premature failure of railroad axles at stresses below the elastic limit (Polák, J. 2003). His work is still used in the form of $\mathrm{SN}$-curves. The problem however is that these curves should be updated for every project where a different design approach or installation procedure is used. Of course, this is mostly not the case leading to a misunderstanding of the fatigue behaviour of the detail being studied. Additionally, the Palmgren-Miner method is used to calculate the lifetime of that detail. The most important advantage of this method is its simplicity while giving a good indication of the remaining lifetime. However, this method is not very accurate because the load history and the load sequences do not have any effect on the fatigue behaviour. These design imperfections lead to overestimating the dimensions when considering orthotropic bridge deck plates.

Orthotropic bridge decks are widely used in long span steel bridges since they are extremely light weighted when compared with the load carrying capacity and are therefore durable and very efficient. These types of bridge decks consist out of a complex network of closed trapezoidal longitudinal stiffeners and transverse web stiffeners welded to a deck plate (Fig. 1).

Because of the latter, various complex welding operations cause multiple fatigue problems across

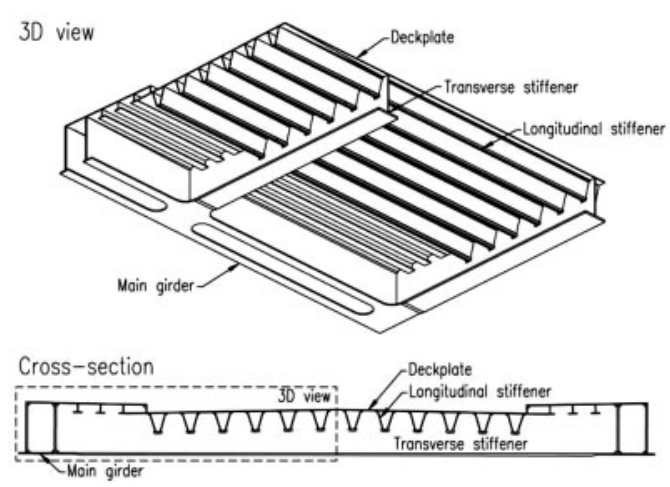

Figure 1. Cross-section and $3 \mathrm{~d}$ view of an orthotropic bridge deck.

the bridge deck. To investigate the complex fatigue behaviour, other methods are needed besides the traditional way of fatigue calculation. Therefore, a more in-depth analysis is used: fracture mechanics. This method is well known in the aerospace, marine and automobile sector because it can evaluate the crack behaviour in detail. Also a much larger dataset will be available for estimating the total fatigue lifetime or even a more realistic evaluation for the remaining lifetime of existing bridges.

\section{DESCRIPITION OF THE PROBLEM}

In the past 10 years, several fatigue problems have been observed in several orthotropic bridge decks across Europe. Especially in the Netherlands, where many of 


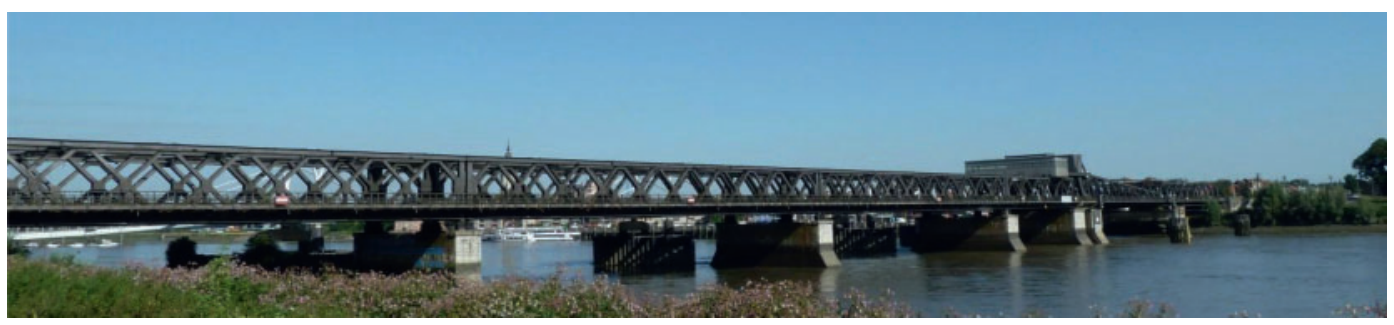

Figure 2. The Temse bridge across the river Scheldt (Belgium).

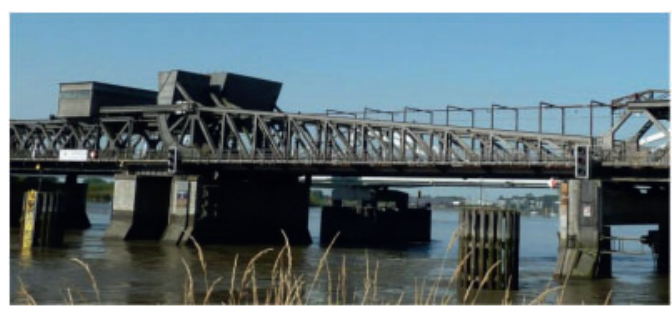

Figure 3. Movable part of the Temse bridge.

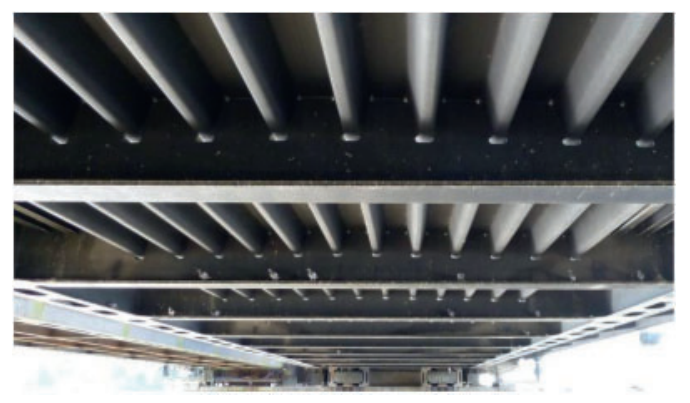

Figure 4. Orthotropic deck plate of the Temse bridge.

these bridge decks were constructed (Maljaars, J. et al. 2012). An example in Belgium described in this article, is the Temse bridge across the river Scheldt (Figs 24). Fatigue problems are mostly due to the lack of understanding of the fatigue behaviour. Additionally, the traffic intensity and also the traffic loads increased a lot since the construction of these bridge decks. But even recent constructed bridges could develop fatigue cracks (Maljaars, J. et al. 2012). This confirms that a more in-depth analysis is needed. In addition, fatigue cracks often initiate at the weld root. So, in the case of a stiffener-to-deck plate connection with closed stiffeners, the crack would propagate without any possible detection through visual inspection. Therefore, the fatigue crack would only be visible when there is already considerable damage.

\section{CASE STUDY}

An example of an orthotropic bridge deck with a poor fatigue behaviour is the Temse bridge across the river Scheldt in Belgium. This bridge is part of an important transport route for heavy lorries to the port of Antwerp.

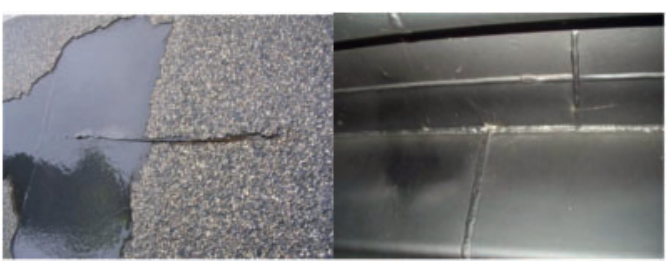

Figure 5. Longitudinal crack through the deck plate at a stiffener-to-deck plate connection (left), multiple welds intersecting at the crack location (right).

The Temse bridge was built in 1955. Initially, the movable part had an aluminium deck plate. After many repairs, the movable part however was rebuilt in 1994 using a steel orthotropic plated deck (Fig. 4).

The deck plate of this movable part of the bridge is $12 \mathrm{~mm}$ thick and the stiffeners are $8 \mathrm{~mm}$ thick. The overall dimensions of the traffic lane are $53,90 \mathrm{~m}$ by $7,00 \mathrm{~m}$. The trapezoidal stiffeners are $350 \mathrm{~mm}$ high and $300 \mathrm{~mm}$ wide on top and $90 \mathrm{~mm}$ width of the lower soffit. The distance between the longitudinal stiffeners equals $300 \mathrm{~mm}$.

In 2004, a $600 \mathrm{~mm}$ long crack was detected in the stiffener-to-deck plate detail mid-span between two crossbeams (Fig. 5). The main reason for this crack is the occurrence of multiple welds intersecting one another (Van Bogaert, Ph. \& De Backer, H. 2008, Nagy, W. et al. 2012). In addition, these welds were not chamfered and even the in the design demanded lack of penetration can be questioned here. In this particular case, the crack propagated through the deck plate starting from the weld root. Even when the crack had penetrated the deck surface, still no visible damage could be detected at the through because of the location of the crack initiation. With these cracks, there is already sufficient damage when the crack front occurs at the deck surface. A this stage, the crack is not stable anymore and propagates proportionally. Because the crack front occurs close to the high traffic loads, the crack has been repaired immediately (Van Bogaert, Ph. \& De Backer, H. 2008).

\section{ANALYTICAL STUDY}

\subsection{General}

To verify the fatigue problem in detail, a more sophisticated method is needed instead of the traditional 


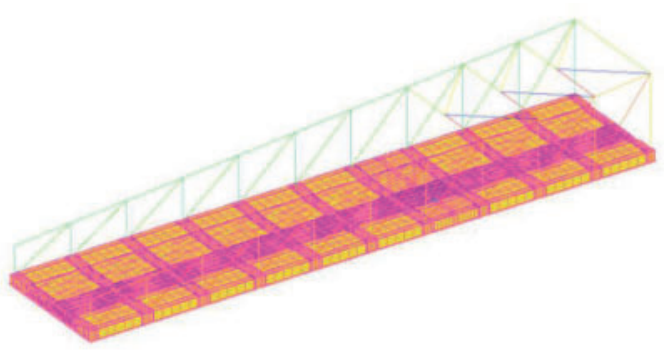

Figure 6. Large FEM-model of the Temse bridge.

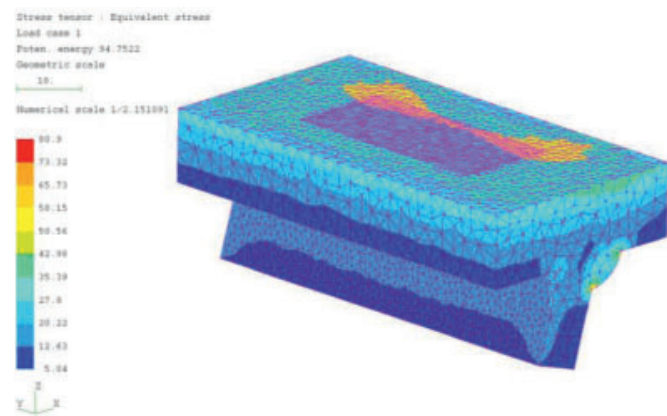

Figure 7. Von Misses stresses of the detailed small-scale model.

SN-curves and the Palmgren-Miner hypothesis as already explained. Therefore, the use of fracture mechanics could give a more detailed and improved look at the problem. To analyse the stiffener-to-deck plate connection detail, a FEM-model was developed in the finite element software Samcef. The advantage of using such software, is the ability to evaluate several fracture mechanics parameters and the crack propagation as well. This is done with an XFEM (eXtended Finite Element Method) method. With this method, the crack growth can be assessed without re-meshing the model in the vicinity of the crack. Although this is a very helpful tool, it needs a huge amount of computation time and power. Especially when the model is complex or when large cracks need to be evaluated.

\subsection{FEM-model}

In a first stage, a FEM-model is built of the whole movable part of the Temse bridge (Fig. 6). This is done with shell elements and beams. Although this model reflects the real behaviour of the structure well, a more detailed model is needed for studying the fracture mechanics parameters. Therefore, a more detailed small-scale model is constructed consisting of volume elements (Fig. 7).

To relate both models, the displacements and rotations are taken from the first model and introduced on the boundaries of the detailed model. This also implies that the big model is reduced to only the detail being studied, and that the computation time decreases.

\subsection{XFEM-model}

\subsubsection{Manual model}

Two possible ways to assess the fatigue life of welded connections with an XFEM-model exist. The first option is to insert a certain number of crack fronts in the weld corresponding to the crack front detected in a damaged detail of a construction. For this case study, an initial elliptical crack of $1 \mathrm{~mm}$ (both axes) was inserted at the weld root and perpendicular to the bridge deck (Fig. 9). The choice of this initial crack length could have a great influence on the total fatigue life of the structure. Depending on the welding detail, used construction technologies, lifetime of the structure, etc. an initial crack between $0,1 \mathrm{~mm}$ and $1 \mathrm{~mm}$ is often chosen (Polák, J. 2003, Nagy, W. et al. 2012). The reason why a $1 \mathrm{~mm}$ crack is assumed for this case study relies on a microscopic study of present weld details of a stiffener-to-deck plate connection (De Backer, H. 2006). The difference between several manufacturers is also taken into account.

After the fracture mechanics parameters are gathered from this initial crack, several other crack fronts could be evaluated with incrementing dimensions. An important parameter to evaluate is the stress intensity factor (SIF). This parameter can be used to evaluate the crack growth and its lifetime using one of the many crack propagation laws. In this case, the traditional Paris law is used:

$\frac{d a}{d N}=C \cdot \Delta K_{I}^{m}$

where $C$ and $m$ are material properties and $\Delta K_{I}$ represents the stress intensity factor for mode I cracks. For structural steel $C$ equals $3 \cdot 10^{-13}[\mathrm{~N}, \mathrm{~mm}]$ and $m$ equals 3 [-] (Maljaars, J. et al. 2012). For the assessment of existing (old) steel bridges, $C=4 \cdot 10^{-13}$ and $m=3$ could be used (Kühn, B. et al. 2008).

Knowing the SIF-values for a certain number of crack fronts, it is possible to simulate the geometrical depended parameter $f(a)$ from equation 2 :

$$
\Delta K_{I}=f(a) \cdot \Delta \sigma \cdot \sqrt{\pi \cdot a}
$$

In this equation $\Delta \sigma$ represents the applied stress range at the crack front and $a$ the crack length. The geometrical parameter $f(a)$ not only depends on the crack length $a$, but also on the overall dimensions of the bridge deck. Therefore, once this parameter is evaluated for a particular bridge deck geometry and weld detail, this could be used for several other bridges with comparable dimensions.

Finally in order to get more realistic results, the Paris law could be expanded with the threshold value of the SIF-value:

$$
\frac{d a}{d N}=C \cdot\left(\Delta K_{I}^{m}-\Delta K_{t h}^{m}\right)
$$

This threshold value lies between 61 and $80 \mathrm{~N} / \mathrm{mm}^{3 / 2}$ for structural steel (Maljaars, J. et al. 2012, Kühn, B. et al. 2008). 
From equation 3 it is now possible to evaluate the total fatigue life of the detail being studied:

$N_{f}=\int_{a_{i}}^{a_{f}} \frac{d a}{C \cdot\left(\Delta K_{I}^{m}-\Delta K_{t h}^{m}\right)}$

or:

$N_{f}=\int_{a_{j}}^{a_{f}} \frac{d a}{C \cdot\left((f(a) \cdot \Delta \sigma \cdot \sqrt{\pi \cdot a})^{m}-\Delta K_{t h}{ }^{m}\right)}$

\subsubsection{Automatic model}

A second and more accurate option to evaluate the crack front is with an automatic crack propagation method using the full advantage of the XFEM possibilities. Generally, the principle is the same as with the manual method. At first, an initial crack is placed in the model. After that, the XFEM-model uses the Paris law in order to propagate the crack automatically according to the path which uses the least energy to crack:

$\frac{d a}{d N}=C \cdot\left(\Delta K_{I}^{e f f}\right)^{n}$

The SIF-value in this equation is a function of $\Delta K_{I}, \Delta K_{I I}, \Delta K_{I I I}, \theta_{p}$ (bifurcation angle) and the used material.

Besides the SIF-values and the fatigue lifetime, this method also gives the crack propagation path in a complex three-dimensional way. This is a great advantage in evaluating the weld geometry and their resulting cracks. The only disadvantage of this method is the computational effort. This method only gives accurate results if the mesh is sufficient fine enough around the crack front. Therefore, only relative small cracks could be evaluated with this method.

\section{RESULTS}

Before the XFEM analysis, a FEM analysis is done of the orthotropic bridge deck of the Temse bridge. Figure 7 illustrates the Von Misses stresses in the geometrical detail of the weld, while Figure 8 represents the third principal stresses of a cross section of the detail midspan two crossbeams.

Figure 8 also indicates a zone of compression at the weld root, which is the location of the initial crack for the XFEM calculation. Therefore, the crack propagation is due to compression and not tension.

According to a traditional fatigue analysis of this bridge deck (De Backer, H. et al. 2006), a total fatigue life of 23,8 years is observed. This incredibly small result indicates that it is obvious that a crack length of $600 \mathrm{~mm}$ was detected after 10 years of service life. One of the reasons of this poor result relies on the fact that only a very thin surface layer of $8 \mathrm{~mm}$ is used. And as Figure 5 indicates, the deck is already damaged at the crack location in a way that no load dispersion could be possible.

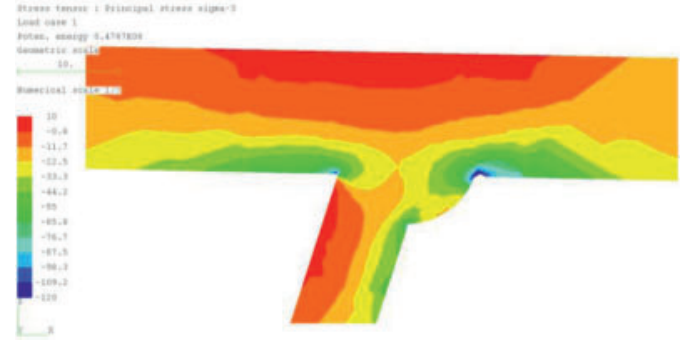

Figure 8. Third principal stresses of a cross-section of the detailed small-scale model.

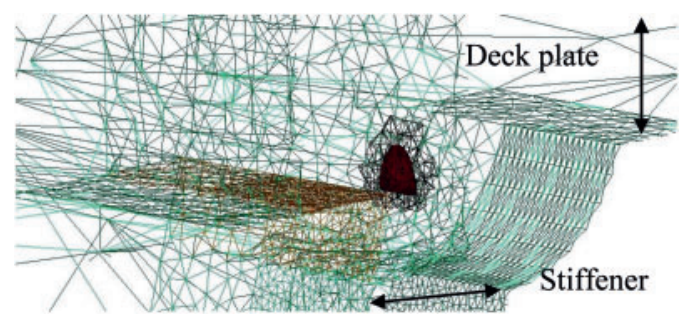

Figure 9. Initial semi-elliptical crack length of $1 \mathrm{~mm}$ on both axes.

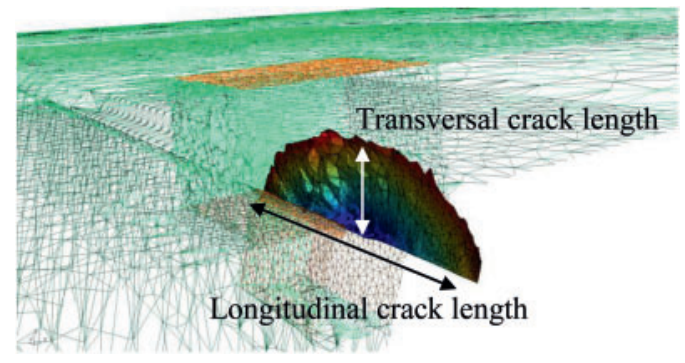

Figure 10. Large crack length developed through the deck plate.

\subsection{Manual XFEM-model}

The calculations with the manual XFEM method are done with an initial semi-elliptical crack length of $1 \mathrm{~mm}$ as already explained (Fig. 9). In addition, several other cracks with incremented dimensions are evaluated like the larger crack front in Figure 10.

Concerning the applied stresses, model 4 is used conform the Eurocodes (Structural Eurocodes 2010). This implies that a traffic distribution is used with five characteristic lorries. Figure 11 illustrates the location of the corresponding axle loads in relation with the crack location. As a result, Figure 12 and Figure 13 illustrate the SIF-values for all the crack geometries being studied. A best-fit curve could be found representing the formulation for the geometrical parameter $f(a)$. Therefore, all the SIF-values are known for every crack length and different axle loads. It is also visible 

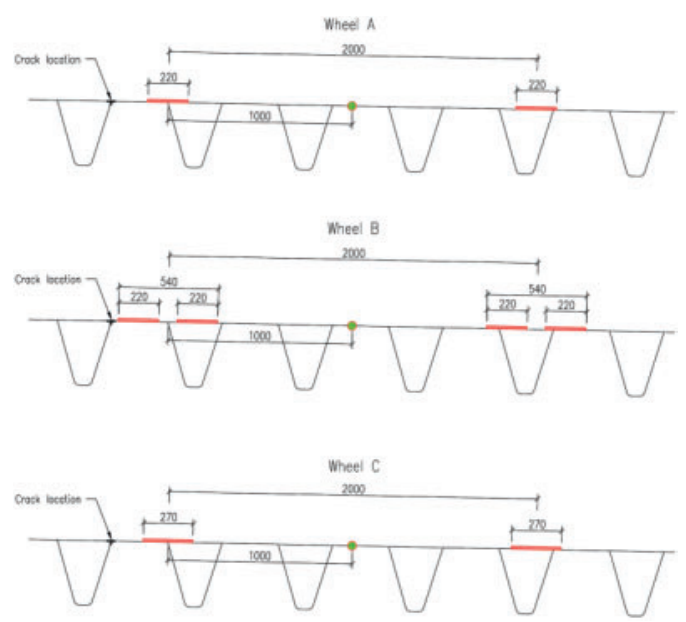

Figure 11. Position of the axle loads in relation with the crack location.

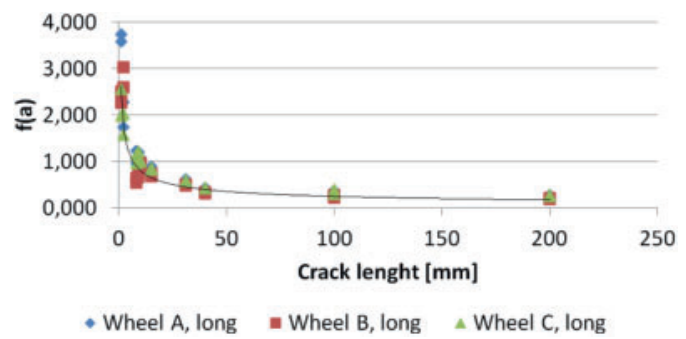

Figure 12. Geometrical parameter $f(a)$ for the longitudinal crack propagation.

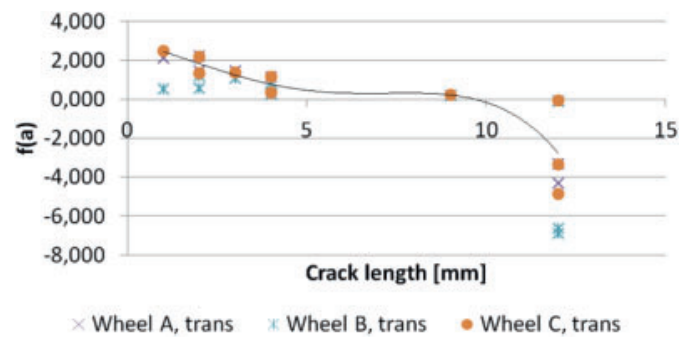

Figure 13. Geometrical parameter $f(a)$ for the transversal crack propagation.

that the crack would propagate much faster in the longitudinal direction and not so fast in the transversal. The crack only propagates much faster transversally, when the crack front counters the tensile zone of Figure 8 . This indicates that the crack first propagates longitudinal through the weld before propagating through the deck plate, which confirms the problem of visual inspection of fatigue cracks.

It is known that during the past service live of 10 years, where the crack propagated until the crack length of $600 \mathrm{~mm}$, an approximate load cycle history is equal to:

$N=10$ years $\cdot 250$ days $\cdot 2800 \frac{\text { lorries }}{\text { day }}=7 \cdot 10^{6}$

The corresponding fatigue crack with these load cycles could be derived from equation 2 and 3 :

$a=\sum_{i} C \cdot\left(\left(f\left(a_{i}\right) \cdot \Delta \sigma_{i} \cdot{\sqrt{\pi \cdot a_{i}}}\right)^{m}-\Delta K_{t h}{ }^{m}\right) \cdot d N$

With this equation, a longitudinal fatigue crack length of $461,703 \mathrm{~mm}$ could be found for the $7.10^{6}$ lorries and 10 years of service life. This is smaller than the $600 \mathrm{~mm}$ detected in real life, but it must be said that a FEM-model is still an ideal environment with no inhomogeneities. In addition, this model does not take into account any residual stresses, which are most likely present in the weld. Especially because multiple welds intersect at the crack location (Fig. 5) and the welds are not chamfered or treated at the surface to reduce any residual stresses.

\subsection{Automatic XFEM-model}

As with the manual method, an initial crack length of $1 \mathrm{~mm}$ was chosen. Although only a small crack propagation of several $\mathrm{mm}$ could be simulated due to the heavy computation time, a clear indication of the crack propagation patch becomes visible. The crack seems to propagate through the weld itself and not through the deck plate. This is not so peculiar because the largest stresses are within the weld throat itself and not in the deck plate (Fig. 8). Why the crack path is different for the crack in real life could be for the same reasons of the manual calculations. Residual stresses have a great influence on the crack initiation stage and also on the crack propagation.

\section{CONCLUSIONS}

It becomes clear that fracture mechanics as an improvement of the fatigue life assessment in orthotropic bridge decks has many advantages. In the traditional fatigue calculations, there are too many assumptions and simplifications to get accurate results. Especially when different geometries or construction technologies are used. Fracture mechanics on the other hand makes it possible to evaluate every detail separately, this being less conservative. In addition, once a particular detail is properly studied, a geometrical parameter $f(a)$ imposes itself. Therefore, other similar details could be evaluated without doing an intensive FEM and XFEM calculation.

Application of this method to the case of the Temse bridge in Belgium, resulted in a crack length of $461,703 \mathrm{~mm}$ after a service life of 10 years. Compared to the $600 \mathrm{~mm}$ of crack length found in reality, this is a good result although a bit optimistic. A possible 
explanation is that the model does not take any residual stresses into account. The implementation of such stresses in the model could be an improvement for further research.

\section{REFERENCES}

De Backer, H., Van Bogaert, Ph. \& Outtier, A. 2006. Fatigue cracks in orthotropic decks: possible alternatives. Proc. 6th international Symposium Steel Bridges, Prague, 2006: $1-10$.

De Backer, H. 2006. Optimalisatie van het vermoeiingsgedrag van het orthotroop brugdekconcept door verbeterde dispersie van de verkeersbelasting. Universiteit Gent.

Kühn, B., Lukic, M., Nussbaumer, A., Günther, H.-P., Helmerich, R., Herion, S., Kolstein, M.H., Walbridge, S., Androic, B., Dijkstra, O. \& Bucak, Ö. 2008. Assessment of Existing Steel Structures: Recommendations for Estimation of Remaining Fatigue Life. JRC-ECCS.

Maljaars, J., van Dooren, F. \& Kolstein, H. 2012. Fatigue assessment for deck plates in orthotropic bridge deck. Steel Construction 5, No. 2: 93-100.

Nagy, W., De Backer, H. \& Van Bogaert, Ph. 2012. Crack propagation in a stiffener-to-deckplate connection of an orthotropic steel bridge deck. Proc. 19th European Conference on Fracture. Kazan, Russia: 2012.

Polák, J. 2003. Comprehensive Structural Integrity. Volume 4: Cyclic Loading and Fatigue. Elsevier Ltd.

Structural Eurocodes 2010. Eurocode 1: Actions on structures - Part 2: Traffic loads on bridges. EN 19912:2003/AC:2010 2010

Van Bogaert, Ph. \& De Backer, H. 2008. Early fatigue damage and repair of steel orthotropic plated bridge deck. Proc. 5th European Conference on Steel and Composite Structures. Graz, Austria 2008: 851-856. 